\title{
ChemComm
}

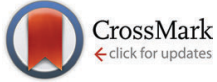

Cite this: Chem. Commun., 2017. 53,1164

Received 8th November 2016 Accepted 21st December 2016

DOI: $10.1039 / c 6 c c 08939 a$

www.rsc.org/chemcomm

\section{Fullerene-free polymer solar cells processed from non-halogenated solvents in air with PCE of $4.8 \% \dagger$}

\author{
Sergey V. Dayneko, Arthur D. Hendsbee and Gregory C. Welch*
}

\begin{abstract}
Progress towards practical organic solar cells amenable to large scale production is reported. Fullerene-free organic solar cells with a PCE of $\sim 4.8 \%$ are achieved based upon an active layer composed of the standard donor polymer PTB7-Th and a highly soluble twisted PDI acceptor tPDI-Hex. All devices can be fabricated and tested in air with 'as-cast' active layers being processed from the greener solvents o-xylene (or trimethyl benzene) or the eco-friendly and bio-derived solvent $2 \mathrm{Me}-\mathrm{THF}$ without loss in efficiency.
\end{abstract}

Finding affordable and efficient methods to directly harness the energy of the sun is a grand challenge for scientists and engineers in today's world. Chemists are making an impact in this area by developing molecules, materials, and processes that utilize the sun's energy to catalyse reactions, create gaseous and liquid fuels, and produce electricity. With respect to the latter, solar photovoltaics based upon organic materials are a promising clean energy technology. Such organic solar cells (OSCs) utilize organic materials as active components to absorb light, generate free charges, and transport electrons. The use of organic active layers allows for low temperature solution deposition, enabling fabrication onto lightweight and flexible substrates. In addition, these OSCs can be colour tuned and made semi-transparent, opening up opportunities for solar windows. ${ }^{1,2}$

Polymer based bulk-heterojunction (BHJ) OCSs are the most widely studied and are considered state-of-the-art. ${ }^{3}$ Power conversion efficiencies (PCEs) of $10 \%$ have been reported for both fullerene ${ }^{4-6}$ and fullerene-free ${ }^{7-9}$ based solar cell devices. While encouraging, these performance metrics are often achieved without regard for the cost, sustainability, and 'greenness' of the materials, processing, and device fabrication. OCS are often championed as being an ultra-low cost technology but best performing devices typically rely on organic materials with complicated and expensive synthesis, chlorinated

Department of Chemistry, University of Calgary, 2500 University Drive N.W., Calgary, Alberta,T2N 1N4, Canada.E-mail: gregory.welch@ucalgary.ca

$\dagger$ Electronic supplementary information (ESI) available: Experimental details, details on device fabrication and testing, optical absorption and emission spectroscopy. See DOI: 10.1039/c6cc08939a processing solvents, high temperature processing, and the need to fabricate and test devices in an inert atmosphere. ${ }^{10-12}$

While the concept of green and/or sustainable OCSs has been proposed in the past, ${ }^{13}$ in has only been very recently that select research groups have begun to recognize the importance of this concept. Leclerc has been developing atom-economical synthetic pathways towards $\pi$-conjugated polymers ${ }^{14-16}$ while others have disclosed high PCE devices base upon simple active layer materials, ${ }^{17-20}$ devices processed from non-halogenated solvents, ${ }^{4,21-23}$ and even air processing and testing. ${ }^{24,25}$ Our research group has had a long interest in developing sustainable materials and processes for organic electronics. ${ }^{26-28}$ Herein we report on fullerene-free OSC devices that use a scalable and low-cost electron acceptor, greener processing solvents, and are processed and tested in air. Our results will help move the community one step closer towards ultra-low cost and sustainable organic photovoltaics (PV).

For this study we utilized an active layer based upon the polymer PTB7-Th and the twisted perylene diimide (PDI) dimer tPDI-Hex (Fig. 1). PTB7-Th ${ }^{29}$ is a high performance narrow band gap donor polymer that is emerging as a standard in the fabrication of fullerene-free OSCs. ${ }^{30-32}$ tPDI-Hex has recently been reported by our group and used as an acceptor in BHJ OCSs. ${ }^{33}$ An important
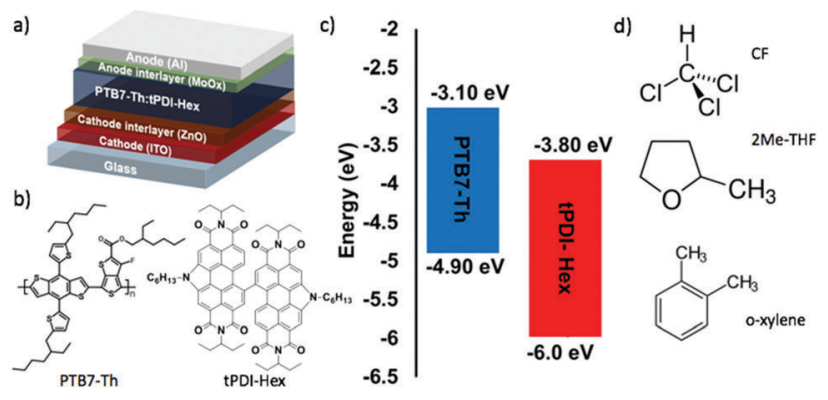

Fig. 1 (a) Solar cell device architecture. (b) Structures of the PTB7-Th donor and tPDI-Hex acceptor. (c) Schematic energy level of PTB7-Th and TPDI-Hex. (d) Chemical structures of the solvents chloroform (CF), 2-methyltetrahydrofuran (2Me-THF) and o-xylene in this work. 
feature of this compound is the N-annulation at the bay position of the PDI chromophore which allows for incorporation of alkyl groups, dramatically improving materials solubility. ${ }^{34,35}$ In addition, we have demonstrated that tPDI-Hex can be synthesized on multi-gram scale in high yield without the need for column-chromatography purification, starting from low-cost and readily availed starting materials (Fig. S3 and Table S2, ESI $\dagger$ ). These features make tPDIHex and its derivatives attractive for upscaling. PTB7-Th and tPDI-Hex have complimentary optical absorption profiles and electronic energy levels making them an ideal donor/acceptor BHJ pair (Fig. S1, ESI $\dagger$ ). In our previous report, ${ }^{33}$ PCEs of $5 \%$ were achieved using a derivative of tPDI-Hex and PTB7-Th as the active layer components, although chlorobenzene was used as the processing solvent and all devices were fabricated in an inert atmosphere which are non-ideal for large scale manufacturing. Moving towards more practical organic PVs we wanted to explore the use of greener solvents for active layer processing in air. Remarkably, PCEs of $4.8 \%$ can be achieved for BHJ OSCs with an inverted structure based on PTB7-Th:tPDI-Hex blend films processed in air under ambient conditions from the halogen-free solvents 2-methyltetrahydrofuran (2Me-THF) or $o$-xylene (Fig. 1) without the use of additives or post-deposition treatments (i.e. thermal or solvent annealing, or solvent treatments). These PCE values are comparable to those of control devices with active layers processed from chloroform (CF).

OSCs were fabricated with an inverted architecture (ITO/ZnO/ PTB7-Th : tPDI-Hex/ $\mathrm{MoO}_{x} / \mathrm{Ag}$ ) owing to the ease of manufacturing and proven environmental stability (Fig. 1a). ${ }^{36} \mathrm{ZnO}$ films were prepared by spin-casting a solution of the mixture of 2-methoxyethanol and ethanolamine on top of ITO and then sintering at $200{ }^{\circ} \mathrm{C}$ in air. The active layer was coated on top via spin-coating solutions containing the mixed PTB7-Th: tPDI-Hex materials with a weight ratio of $2: 3$ or $3: 7$ and total concentration $10 \mathrm{mg} \mathrm{ml}^{-1}$ in air. Film thickness was $\sim 90 \mathrm{~nm}$ for all films as determined by atomic force microscopy (AFM). A high acceptor loading is favoured owing to the relatively simpler (i.e. lower cost) synthetic procedure and higher solubility of tPDI-Hex compared to PTB7-Th. Finally, a $\mathrm{MoO}_{x} / \mathrm{Ag}$ top electrode for the device was applied by thermal deposition in vacuum. For complete fabrication details, see the ESI. $\dagger$ For the processing solvents we selected chloroform (CF) as a control solvent owing to is wide spread use, high solubilizing power, and ability to allow for uniform film formation. 2Me-THF and $o$-xylene were selected as they are both non-halogenated and thus relatively less toxic, $o$-xylene is high boiling and good for large area processing ${ }^{37,38}$ while $2 \mathrm{Me}$-THF has can readily dissolve our materials and is an eco-friendly and biomass derived solvent. ${ }^{39}$ 1,2,4-Trimethyl benzene (TMB) was also evaluated owing to its recent use in the fabrication of record efficiency OCSs. ${ }^{4}$ Relevant details on each solvent is provided in Table S1 (ESI $\dagger$ ). All active layers were processed in air and OSC devices tested in air to simplify the overall procedure.

Current density-voltage $(J-V)$ characteristics of OSCs measured under simulated AM 1.5G irradiation with intensity of $100 \mathrm{~mW} \mathrm{~cm}^{-2}$ are shown in Fig. 2. The device parameters of the open circuit voltage $\left(V_{\mathrm{oc}}\right)$, the short circuit current $\left(J_{\mathrm{sc}}\right)$, the fill factor $(\mathrm{FF})$, and the power conversion efficiency (PCE) are summarized in Table 1.
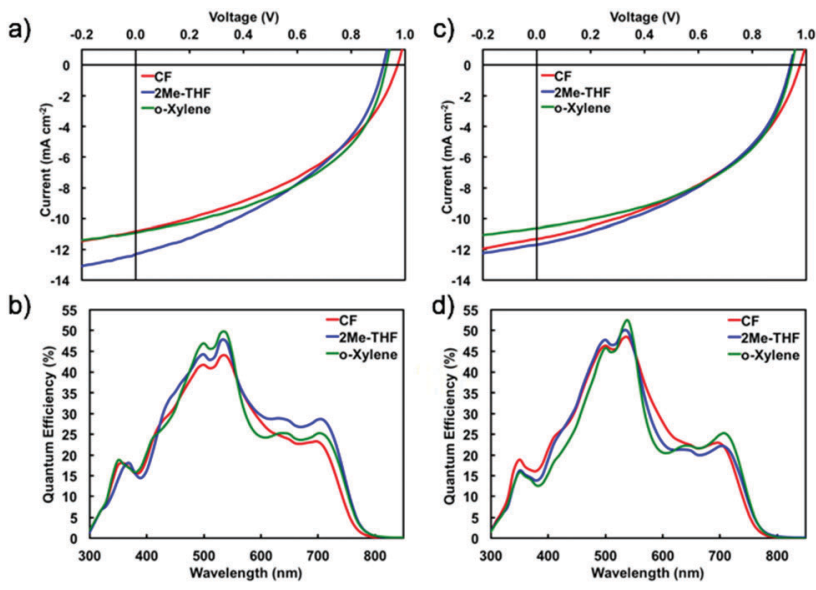

Fig. $2 J-V$ characteristics (a and c) and EQE spectra (b and d) of OSCs with an inverted structure based on PTB7-Th: tPDI-Hex blend films obtained from chloroform (CF) or halogen-free solvent (2Me-THF and o-xylene) at 2:3 ( $\mathrm{a}$ and $\mathrm{b}$ ) and $3: 7$ ( $\mathrm{c}$ and $\mathrm{d}$ ) donor: acceptor ratios.

Series and shunt resistances are listed in Table S4 (ESI $\dagger$ ). OSCs with 'as-cast' active layers processed from CF exhibited high PCEs approaching 5\%. The optimal weight ratio of PTB7-Th: tPDI-Hex was $2: 3$ in this case. This BHJ OSC showed a PCE of $4.8 \%$ with $V_{\text {oc }}$ of $0.97 \mathrm{~V}, J_{\mathrm{sc}}$ of $11.3 \mathrm{~mA} \mathrm{~cm}^{-2}$, and $\mathrm{FF}$ of $43.1 \%$. The performance of the OSCs decreased slightly with decreasing concentration of the donor (ratio PTB7-Th: tPDI-Hex of $3: 7$ ). In comparison, BHJ OSC with 'as-cast' active layers processed from $2 \mathrm{Me}-\mathrm{THF}$ or $o$-xylene with different weight ratios of $2: 3$ and $3: 7$ showed PCE of 4.7 and $4.8 \%$, respectively. Here the PCE is maintained using the non-halogenated solvents and weight ratio had a minimal effect on device performance indicating a very insensitive $\mathrm{BHJ}$ active layer. The best $\mathrm{BHJ}$ OSC using $2 \mathrm{Me}-\mathrm{THF}$ showed a PCE of $4.8 \%$ with $V_{\mathrm{oc}}$ of $0.94 \mathrm{~V}, J_{\mathrm{sc}}$ of $11.6 \mathrm{~mA} \mathrm{~cm}^{-2}$, and $\mathrm{FF}$ of $43.7 \%$, while the best BHJ OCS using $o$-xylene showed a PCE of $4.8 \%$ with $V_{\text {oc }}$ of $0.95 \mathrm{~V}, J_{\mathrm{sc}}$ of $10.7 \mathrm{~mA} \mathrm{~cm} \mathrm{~cm}^{-2}$, and $\mathrm{FF}$ of $47.6 \%$. In both case a $3: 7$ weight ratio of donor/acceptor proved best. It is quite remarkable that a PCE of $4.8 \%$ can be achieved using such simple processing conditions with a high acceptor concentration. Use of TMB as a processing solvent gave similar results with $\mathrm{PCE}=4.6 \%$, full details can be found in the ESI. $\dagger$

Fig. $2 \mathrm{~b}$ and d displays external quantum efficiency (EQE) spectra of the OSCs obtained from various solvents at the different donor/acceptor ratios. All EQE spectra have similar

Table 1 Summary of device parameters of OSCs with an inverted structure based on PTB7-Th: tPDI-Hex 'as-cast' blend films obtained from neat CF, 2Me-THF, o-xylene, or TMB solvents at different donor/acceptor ratios under AM 1.5G illumination at $100 \mathrm{~mW} \mathrm{~cm}^{-2}$. Calculated series and shunt resistance are found in Table S4 (ESI)

\begin{tabular}{llllll}
\hline Solvent & $\begin{array}{l}\text { PTB7-Th: tPDI-Hex } \\
{[\mathrm{wt} / \mathrm{wt}]}\end{array}$ & $\begin{array}{l}V_{\mathrm{oc}} \\
{[\mathrm{V}]}\end{array}$ & $\begin{array}{l}J_{\mathrm{sc}} \\
{\left[\mathrm{mA} \mathrm{cm} \mathrm{cm}^{-2}\right]}\end{array}$ & $\begin{array}{l}\mathrm{FF} \\
{[\%]}\end{array}$ & $\begin{array}{l}\text { PCE } \\
{[\%]}\end{array}$ \\
\hline $\mathrm{CF}$ & $2: 3$ & 0.97 & 11.3 & 43.1 & 4.8 \\
$\mathrm{CF}$ & $3: 7$ & 0.98 & 10.3 & 43.1 & 4.4 \\
2Me-THF & $2: 3$ & 0.92 & 12.3 & 41.2 & 4.7 \\
2Me-THF & $3: 7$ & 0.94 & 11.6 & 43.7 & 4.8 \\
$o$-Xylene & $2: 3$ & 0.93 & 12 & 42.2 & 4.7 \\
$o$-Xylene & $3: 7$ & 0.95 & 10.7 & 47.6 & 4.8 \\
TMB & $3: 7$ & 0.95 & 10.8 & 44.6 & 4.6
\end{tabular}



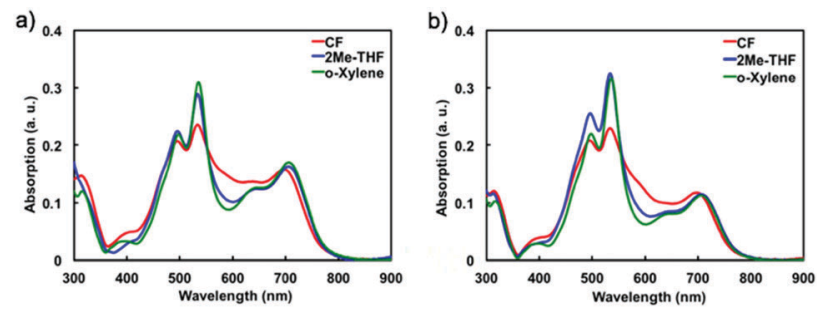

Fig. 3 (a) Absorption spectra of OSCs with an inverted structure based on PTB7-Th : tPDI-Hex blend films obtained from chloroform (CF) or halogen-free solvent (2Me-THF and o-xylene) at (a) 2:3 and (b) 3:7 donor : acceptor ratios.

profiles with photocurrent generation being observed out to $\sim 750 \mathrm{~nm}$ and all spectra having a pronounced maximum in the region from 450 to $500 \mathrm{~nm}$. This maximum corresponds to the absorption of the tPDI-Hex. The EQE spectra in the region from 600 to 750 , which corresponds to contributions from the PTB7-Th, is lower in intensity owing to the lower concentration of PTB7-Th in the films.

The absorption spectra of BHJ organic solar cells based on PTB7-Th : tPDI-Hex blend films obtained from chloroform or halogen-free solvent (2Me-THF and $o$-xylene) at $2: 3$ and $3: 7$ donor/acceptor ratios are shown in Fig. $3 \mathrm{a}$ and b, respectively. The first maxima absorbance $(\lambda=700 \mathrm{~nm})$ corresponding to the PTB7-Th absorption (Fig. S1, ESI $\dagger$ ) are identical indicating similar polymer concentration in each film. There is a difference between the spectra in region from $600 \mathrm{~nm}$ to $450 \mathrm{~nm}$ where the tPDI-Hex absorption occurs (Fig. S1, ESI $\dagger$ ). Neat films of tPDIHex spin-cast from CF exhibit two equal intensity bands from 450-550 nm, attributed to the $0-0$ and $0-1$ transitions and a shoulder at $600 \mathrm{~nm}$. In contrast neat films of tPDI-Hex spin-cast from either 2Me-THF or $o$-xylenes show two sharp bands of considerable higher intensity from $450-550 \mathrm{~nm}$ but no low energy shoulder, thus indicating a slightly different molecular arrangement (see Fig. S4, ESI $\dagger$ for further details). This is likely a result of the slower drying time afforded by the non-halogenated solvents. In the blended films these slight differences are present where the CF processed films show higher absorption at $600 \mathrm{~nm}$ but less from $450-550 \mathrm{~nm}$. This is reflected in the EQE where a stronger contribution to photocurrent generation is observed from $450-550$ for those OSCs with active layers cast from 2Me-THF or $o$-xylene.

The photoluminescence (PL) spectra of the tPDI-Hex, PTB7$\mathrm{Th}$ and $\mathrm{BHJ}$ films normalized at excitation wavelength of 530 and $630 \mathrm{~nm}$ is shown in Fig. S2 (ESI $\dagger$ ). These wavelengths are selected to effectively excite in the first case the tPDI-Hex $\left(\lambda_{\mathrm{ex}}=530 \mathrm{~nm}\right.$, Fig. S1, ESI $\left.\dagger\right)$ and in the second PTB7-Th $\left(\lambda_{\mathrm{ex}}=630 \mathrm{~nm}\right.$, Fig. S1, ESI $\left.\dagger\right)$. The intensity of PL spectra of the PTB7-Th : tPDI-Hex blend films dramatically decrease compared with the individual components for both wavelengths. This indicates efficient charge transfer occurs from both donor to acceptor and acceptor to donor, confirming that both channel I and channel II processes are occurring. ${ }^{40,41}$

AFM was used to investigate the morphologies of PTB7-Th: tPDI-Hex blend films (Fig. 4). The PTB7-Th : tPDI-Hex blend films obtained from CF or halogen-free solvent (2Me-THF and $o$-xylene) at $2: 3$ and $3: 7$ donor/acceptor ratios shows smooth and uniform
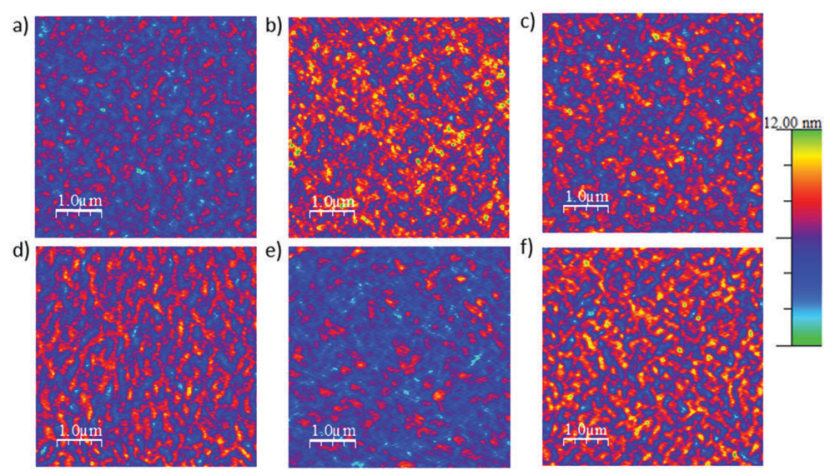

Fig. 4 (a) Non-contact AFM surface scans (size: $5 \times 5 \mu \mathrm{m}$ ) of the PTB7-Th: tPDI-Hex films with $2: 3$ ratio obtained from (a) CF (RMS $=0.99 \mathrm{~nm}$ ), (b) $2 \mathrm{Me}-\mathrm{THF}(\mathrm{RMS}=1.3 \mathrm{~nm}$ ) and (c) o-xylene (RMS = $1.23 \mathrm{~nm}$ ). Noncontact AFM surface scans (size: $5 \times 5 \mu \mathrm{m}$ ) of the PTB7-Th : tPDI-Hex films with 3:7 ratio obtained from (d) CF (RMS $=1.18 \mathrm{~nm}),(e) 2 \mathrm{Me}-\mathrm{THF}(\mathrm{RMS}=$ $1.04 \mathrm{~nm}$ ) and $(\mathrm{f}) \mathrm{o}$-xylene (RMS $=1.37 \mathrm{~nm}$ ). Lower limit of scale is $0 \mathrm{~nm}$.

surface morphology. The value of root mean square (RMS) roughness of PTB7-Th: tPDI-Hex films spin-coated from CF at $2: 3$ and $3: 7$ ratios is $\sim 0.99$ and $\sim 1.18 \mathrm{~nm}$, respectively. When $2 \mathrm{Me}-\mathrm{THF}$ and $o$-xylene were used as the solvents, no significant difference regarding the surface morphology was observed in comparison with PTB7-Th:tPDI-Hex films obtained from CF. All PTB7-Th: tPDI-Hex films shows smooth surface with RMS range from 0.9 to $1.4 \mathrm{~nm}$ and have favourable phase separation. This again reinforces the notion that this BHJ pair is fairly insensitive to processing conditions making it a great candidate for large area device fabrication using non spin coating methods. ${ }^{42}$

In conclusion we have reported on the creation of fullerene-free BHJ organic solar cells that can achieve PCE of $4.8 \%$ with 'as-cast' active layers processed from greener solvents in air at room temperature. No solvent additives or post-deposition film treatments were used simplifying the film forming process. 2Me-THF, $o$-xylene, and TMB were selected and utilized as 'greener' solvents as they lack halogen atoms rendering them less toxic then halogenated solvents. All organic solar cells fabricated showed remarkably consistent morphology and performance metrics regardless of the solvent chosen indicating an insensitive BHJ active layer. This should prove attractive for solar cell upscaling and device reproducibility. Importantly this is the first report of high PCE BHJ organic solar cells processed from the ecofriendly 2Me-THF solvent. We do note that a common theme in the development of high PCE fullerene-free solar cells is the use of complex and expensive donor polymers, and while PTB7Th has many advantages, it must eventually be replaced by a simpler derivate to fully render the system presented suitable for commercialization.

GCW acknowledges NSERC Discovery Grants Program (435715-2013), CFI John Evans Leadership Fund (34102), Canada Research Chairs Program, and the University of Calgary.

\section{References}

1 Y.-W. Su, S.-C. Lan and K.-H. Wei, Mater. Today, 2012, 15, 554-562. 2 R. Søndergaard, M. Hösel, D. Angmo, T. T. Larsen-Olsen and F. C. Krebs, Mater. Today, 2012, 15, 36-49. 
3 G. Li, R. Zhu and Y. Yang, Nat. Photonics, 2012, 6, 153-161.

4 J. Zhao, Y. Li, G. Yang, K. Jiang, H. Lin, H. Ade, W. Ma and H. Yan, Nat. Energy, 2016, 1, 15027.

5 J.-D. Chen, C. Cui, Y.-Q. Li, L. Zhou, Q.-D. Ou, C. Li, Y. Li and J.-X. Tang, Adv. Mater., 2015, 27, 1035-1041.

6 J. You, L. Dou, K. Yoshimura, T. Kato, K. Ohya, T. Moriarty, K. Emery, C.-C. Chen, J. Gao, G. Li and Y. Yang, Nat. Commun., 2013, 4, 1446.

7 W. Zhao, D. Qian, S. Zhang, S. Li, O. Inganäs, F. Gao and J. Hou, Adv. Mater., 2016, 28, 4734-4739.

8 Z. Li, K. Jiang, G. Yang, J. Y. L. Lai, T. Ma, J. Zhao, W. Ma and H. Yan, Nat. Commun., 2016, 7, 13094.

9 J. Liu, S. Chen, D. Qian, B. Gautam, G. Yang, J. Zhao, J. Bergqvist, F. Zhang, W. Ma, H. Ade, O. Inganäs, K. Gundogdu, F. Gao and H. Yan, Nat. Energy, 2016, 1, 16089.

10 A. Marrocchi, A. Facchetti, D. Lanari, C. Petrucci and L. Vaccaro, Energy Environ. Sci., 2016, 9, 763-786.

11 R. Po, A. Bernardi, A. Calabrese, C. Carbonera, G. Corso and A. Pellegrino, Energy Environ. Sci., 2014, 7, 925.

12 S. Liu, Z. Kan, S. Thomas, F. Cruciani, J.-L. Brédas and P. M. Beaujuge, Angew. Chem., Int. Ed., 2016, 55, 12996-13000.

13 D. J. Burke and D. J. Lipomi, Energy Environ. Sci., 2013, 6, 2053.

14 T. Bura, J. T. Blaskovits and M. Leclerc, J. Am. Chem. Soc., 2016, 138, 10056-10071.

15 L. G. Mercier and M. Leclerc, Acc. Chem. Res., 2013, 46, 1597-1605.

16 P. Berrouard, A. Najari, A. Pron, D. Gendron, P.-O. Morin, J.-R. Pouliot, J. Veilleux and M. Leclerc, Angew. Chem., Int. Ed., 2012, 51, 2068-2071.

17 S. Holliday, R. S. Ashraf, A. Wadsworth, D. Baran, S. A. Yousaf, C. B. Nielsen, C.-H. Tan, S. D. Dimitrov, Z. Shang, N. Gasparini, M. Alamoudi, F. Laquai, C. J. Brabec, A. Salleo, J. R. Durrant and I. McCulloch, Nat. Commun., 2016, 7, 11585.

18 P. Josse, C. Dalinot, Y. Jiang, S. Dabos-Seignon, J. Roncali, P. Blanchard and C. Cabanetos, J. Mater. Chem. A, 2016, 4, 250-256.

19 Y. Jiang, C. Cabanetos, M. Allain, P. Liu and J. Roncali, J. Mater. Chem. C, 2015, 3, 5145-5151.

20 J. Roncali, P. Leriche and P. Blanchard, Adv. Mater., 2014, 26, 3821-3838.

21 S. Zhang, L. Ye, H. Zhang and J. Hou, Mater. Today, 2016, 19, 533-543.

22 H. Zhang, H. Yao, W. Zhao, L. Ye and J. Hou, Adv. Energy Mater., 2016, 6, 1502177.
23 D. Liu, Z. Wang, S. Zhang, Z. Zheng, B. Yang, W. Ma and J. Hou, RSC Adv., 2015, 5, 69567-69572.

24 L. Ye, Y. Xiong, H. Yao, A. Gadisa, H. Zhang, S. Li, M. Ghasemi, N. Balar, A. Hunt, B. T. O'Connor, J. Hou and H. Ade, Chem. Mater., 2016, 28, 7451-7458.

25 Y. Guo, Y. Li, O. Awartani, J. Zhao, H. Han, H. Ade, D. Zhao and H. Yan, Adv. Mater., 2016, 28, 8483-8489.

26 S. M. McAfee, J. M. Topple, A.-J. Payne, J.-P. Sun, I. G. Hill and G. C. Welch, ChemPhysChem, 2015, 16, 1190-1202.

27 S. M. McAfee, J. S. J. McCahill, C. M. Macaulay, A. D. Hendsbee and G. C. Welch, $R S C$ Adv., 2015, 5, 26097-26106.

28 S. M. McAfee, J. R. Cann, P. Josse, P. Blanchard, C. Cabanetos and G. C. Welch, ACS Sustainable Chem. Eng., 2016, 4, 3504-3517.

29 S.-H. Liao, H.-J. Jhuo, Y.-S. Cheng and S.-A. Chen, Adv. Mater., 2013, 25, 4766-4771.

30 D. Zhao, Q. Wu, Z. Cai, T. Zheng, W. Chen, J. Lu and L. Yu, Chem. Mater., 2016, 28, 1139-1146.

31 Z. Liu, Y. Wu, Q. Zhang and X. Gao, J. Mater. Chem. A, 2016, 4, 17604-17622.

32 Y. Zang, C.-Z. Li, C.-C. Chueh, S. T. Williams, W. Jiang, Z.-H. Wang, J.-S. Yu and A. K.-Y. Jen, Adv. Mater., 2014, 26, 5708-5714.

33 A. D. Hendsbee, J.-P. Sun, W. K. Law, H. Yan, I. G. Hill, D. M. Spasyuk and G. C. Welch, Chem. Mater., 2016, 28, 7098-7109.

34 Y. Li and Z. Wang, Org. Lett., 2009, 11, 1385-1387.

35 W. Jiang, H. Qian, Y. Li and Z. Wang, J. Org. Chem., 2008, 73, 7369-7372.

36 Y. Sun, J. H. Seo, C. J. Takacs, J. Seifter and A. J. Heeger, Adv. Mater., 2011, 23, 1679-1683.

37 Y. Deng, W. Li, L. Liu, H. Tian, Z. Xie, Y. Geng and F. Wang, Energy Environ. Sci., 2015, 8, 585-591.

38 X. Dong, Y. Deng, H. Tian, Z. Xie, Y. Geng and F. Wang, J. Mater. Chem. A, 2015, 3, 19928-19935.

39 V. Pace, P. Hoyos, L. Castoldi, P. Domínguez de María and A. R. Alcántara, ChemSusChem, 2012, 5, 1369-1379.

40 D. M. Stoltzfus, J. E. Donaghey, A. Armin, P. E. Shaw, P. L. Burn and P. Meredith, Chem. Rev., 2016, 116, 12920-12955.

41 Y. Fang, A. K. Pandey, A. M. Nardes, N. Kopidakis, P. L. Burn and P. Meredith, Adv. Energy Mater., 2013, 3, 54-59.

42 J. G. Tait, T. Merckx, W. Li, C. Wong, R. Gehlhaar, D. Cheyns, M. Turbiez and P. Heremans, Adv. Funct. Mater., 2015, 25, 3393-3398. 